\title{
Challenges of Managing Indigenous Knowledge with other Knowledge Systems for Agricultural Growth in sub-Saharan Africa
}

\author{
Edda Tandi Lwoga, Patrick Ngulube, \\ and Christine Stilwell
}

Dr. Edda Tandi Lwoga, Librarian and Acting

Director, Directorate of Library Services, Muhimbili

University of Health and Allied Sciences, Dar es

Salaam, Tanzania

Email: tlwoga@muhas.ac.tz; tlwoga@gmail.com

Dr. Patrick Ngulube, Professor, School of Graduate

Studies, University of South Africa, Pretoria, South

Africa

Email:ngulup@unisa.ac.za

Dr. Christine Stilwell, Professor, Information

Studies Programme, School of Sociology and Social

Studies, University of KwaZulu-Natal, Scottsville,

South Africa

Email: Stilwell@ukzn.ac.za

\section{Abstract}

This article provides a systematic analysis of the challenges of managing agricultural indigenous knowledge (IK), and accessing external knowledge in the rural areas of sub-Saharan Africa, with a specific focus on Tanzania. Semi-structured interviews were used to collect primary data from 181 smallscale farmers in the six districts of Tanzania. The findings indicated that farmers faced various challenges in managing their IK, and accessing external knowledge, which ranged from personal and social barriers, to factors in the external environment such as infrastructure, policy, Intellectual Property Rights (IPR), and weak linkages between research, extension services and farmers. Farmers also faced challenges when using information and communication technologies (ICTs) to manage their knowledge, such as personal, socio-cultural, infrastructural, technical, and economic factors. It is thus important for the government to improve access to extension services, review the IPR system, enhance rural electrification, telecommunications and roads infrastructure. Further, the knowledge providers (i.e. agricultural extension officers, researchers, educators, libraries, non governmental organisations, civil society, and other agricultural actors) should nurture a knowledge sharing culture. Farmers need to be assisted and trained to document their knowledge, map communities' IK bearers and innovators, use multiple formats (print and ICTs) with traditional communication channels (for instance, folklore and apprenticeships) specific to a local context to disseminate knowledge. Participatory approaches should be employed in knowledge production and dissemination in order to include farmers' needs and expressing knowledge in the resulting technologies, practices and new knowledge. In this way linkages between indigenous and external knowledge would be enhanced for improved farming activities in the local communities.

\section{Background and context}

Indigenous knowledge (IK) is an important asset with regard to the social capital of local people and constitutes the main resource for their livelihoods. The term, indigenous knowledge is often used interchangeably to refer to local knowledge. However, local knowledge refers to the knowledge possessed by any group living off the land in a particular area for a long period of time (Langill 1999). IK on the other hand, while embracing exogenous knowledge which entered the local community over time (van Vlaenderen 2000) differs from local knowledge as the emphasis tends towards knowledge internal to a particular setting. In this context, it is not important whether the people in the local communities are the original inhabitants of an area or not. The aim of the study was to learn how people interact with the environment to improve their knowledge base and farming activities. Thus, this study used the two terms (indigenous and local knowledge) interchangeably to encompass all the above-mentioned terms.

IK is mainly tacit, unique, non-systematic, derived from local experiments, innovations, creativity, skills 
and experiences, and embedded in the minds and activities of communities with long histories of close interaction with the natural environment across cultures and geographical spaces (Ngulube 2002, 95). This knowledge provides communities with a basis for problem-solving strategies in various activities such as agriculture, health, education, and natural resource management. For instance, for centuries IK has been a central feature for improving African agricultural productivity even under difficult conditions (Hårsmar 2007).

Agriculture is an important sector in the economies of most African countries. In Tanzania, agriculture remains fundamental to the national economy, and accounts for 26 percent of gross domestic product (GDP), contributes 95 percent of the total food required in the country, and employs 70 percent of the rural poor (Robinson and Mutakyahwa 2004). IK is an integral part of these agricultural endeavours and figures show that at least 50 percent of the world's population relies on IK for crop and food supplies (Lwoga, Ngulube and Stilwell 2010). In Tanzania, most farmers rely on indigenous farming systems which are estimated at 80 per cent of all the country's agricultural systems (Mella et al. 2007). A study by Lwoga, Ngulube and Stilwell (2010) established that small-scale farmers in Tanzania possess an extensive base of IK and understanding of their environment, and they are able to put appropriate managerial skills and adaptive strategies in place for crop and animal farming and forage resource management. It is clear that the majority of Tanzanian's farmers rely on traditional agricultural methods, in contrast to the minority involved in high-input commercial methods.

Lemma and Hoffmann (2005) suggest that the more the small-scale farmers adapt external technologies and practices to their indigenous practices, the more they innovate and improve their indigenous techniques, skills and practices. External knowledge is the information made available to the rural community from the sources beyond its boundaries as part of the information transfer process to support development (Mchombu 1995). External knowledge is a key component in improving small-scale agricultural production and linking increased production to remunerative markets, thus leading to improved rural livelihoods, improved quality and yield, food security and national economies (Asaba et al. 2006). For instance, Dove (2000) found that the successful production of rubber resulted from the confluence of indigenous and external knowledge in Southeast Asia. Thus, sustainable agricultural development may be better served by a system that unifies both indigenous and external knowledge systems.

In formal agricultural economies in Sub-Saharan countries, including Tanzania (Mascarenhas 2003), external knowledge receives more attention and investments than other knowledge systems. Lack of a cohesive approach for managing knowledge suppresses the efforts of the poor to take advantage of their innovations and skills to improve their farming activities (Lwoga 2011). IK is mainly preserved in the memories of elders, and shared through oral communication and traditional practices and demonstrations. However, each time an elderly person dies it is as if a library has been burned down.

There is still much to be learned from the IK bearers, yet there are inadequate national and organisational efforts to capture this knowledge, and thus it is disappearing at a high rate. At the same time due to weak linkages between research, extension services and farmers, there is still a low rate of adoption of external technologies in Tanzania despite the fact that such technologies receive most of the attention (Ngendello, Mgenzi and Schrader 2003, 143). Hence, farmers neither adopt the new technologies, nor preserve their knowledge systems for future use for their farming activities. There is thus a need to assess the challenges that inhibit farmers from managing their own knowledge and having access to relevant external knowledge for improved farming activities.

Information and communications technologies (ICTs) can also enhance access to relevant external knowledge and the management of IK in the local communities. According to the Geneva Declaration of the Global Forum of Indigenous Peoples and the Information Society, ICTs can be used to strengthen and encourage cultural diversity and to preserve and promote the language, distinct identities and IK of local people, tribes and nations in a way that they determine the best means to advance these objectives (World Summit on the Information Society 2003). Despite their potential role in knowledge management (KM), ICTs can also present challenges to farmers when managing their knowledge and having access to other knowledge systems. Studies have shown that as local people use ICTs to access external knowledge, they tend to ignore their own knowl- 
edge modes and cultures (Lieberman 2008). The digital divide limits local farmers from managing their knowledge through ICTs, due to many factors, which include infrastructural, technical, regulatory, distributional, social, cultural, and economic issues (Lwoga and Ngulube 2008). The challenge is therefore to ensure that ICTs are not used as yet another way to marginalise farmers and their knowledge which was undervalued during the periods of colonial rule.

Efforts are thus needed to enable the same technologies that have negative effects on indigenous cultures to be used to manage IK and embrace a remix of external knowledge for sustainable agricultural practices. This article therefore seeks to establish the barriers to managing agricultural IK and accessing external knowledge both physically and through ICTs in the rural areas of sub-Saharan African countries, with a specific focus on Tanzania. It is with this background that the following research objectives were posed:

- Determine the barriers that hinder the effective acquisition, sharing and preservation of agricultural IK in the local communities.

- Establish the barriers which hinder access to agricultural external knowledge in the local communities.

- Establish the barriers that inhibit the use of ICTs to manage indigenous and external knowledge on farming systems.

\section{Methodology}

The study upon which the article is based used semistructured interviews to collect qualitative and quantitative data from six districts in Tanzania. By direct and detailed observation of farmers in their natural settings qualitative data provided a deep understanding and interpretation of farmers' experience with regard to barriers that inhibit knowledge management (KM) activities in the communities. The quantitative data allowed the patterns which emerged in relation to the barriers to KM activities in the communities to be systematically described. The study used purposive sampling to select research sites and study participants who could yield the necessary information about the topic under investigation (Cohen, Manion and Morrison 2007, 115). Six districts from six regions, in six of seven research zones were se- lected for the study due to their high agriculture production and the presence of ICTs such as telecentres, community radio, and cellular phone networks. Two villages were selected from each of the six districts due to their high agricultural production. These districts and villages included the following: Mpwapwa district (Vinghawe and Mazae villages), Karagwe district (Katwe and Iteera villages), Moshi Rural district (Lyasongoro and Mshiri villages), Kilosa district (Kasiki and Twatwatwa villages), Songea Rural district (Matetereka and Lilondo villages), and Kasulu district (Nyansha and Kidyama villages). A total of 181 smallholder farmers were purposively selected for semi-structured interviews, for which the number of respondents ranged between 27 and 37 per district. The identification of the study participants was based upon discussions with community leaders and local extension officers in each village in order to cover a broad spectrum of farming systems, ethnic-religious groups, gender and age groups. These characteristics were used because variations in knowledge can be observed by the diversity in agro-ecology, ethnicity, population density and infrastructure (Röling 1989). The sampling procedure for interviews continued until the researcher observed that no new additional data was emerging (Teddlie and Tashakkori 2009). Quantitative and qualitative data were analysed separately, and were then combined to compare and validate the findings.

\section{Research findings and discussions}

This section discusses study findings according to the challenges of managing agricultural IK and accessing external knowledge both physically and through ICTs in the rural areas. The respondents' demographic characteristics are also presented.

\section{Profile of respondents}

A total of 181 smallholder farmers (112 men, 69 women) participated in the study. The mean age of the respondents was 48 . The study mainly involved smallholder farmers, with the average farm size of 4.9 acres, where nearly two thirds of the crop farmers, $(61.9 \%$ or 104 , had farm sizes below 4.9 acres. Most respondents (84\%, or 152) had some level of formal schooling, and about $91.2 \%$ (163) could read and understand simple instructions. 
Table 1. Barriers that inhibit the acquisition of agricultural indigenous knowledge. $(\mathrm{N}=181)$

\begin{tabular}{ll}
\hline Barrier & Explanation \\
\hline $\begin{array}{l}\text { Poor recognition of IK } \\
(66.9 \%, \text { or 121) }\end{array}$ & $\begin{array}{l}\text { The study found that farmers perceived IK as an outdated knowledge system. Most youth were not } \\
\text { receptive to IK due to modernisation and a formal education system which showed poor recognition of } \\
\text { IK. The government did not recognise IK, since it lacked plans and structures to prioritise, preserve and } \\
\text { disseminate IK to the communities. For instance, IK was not included in the curriculum of the formal } \\
\text { education system in Tanzania. Agriculture as a subject was included in selected secondary and primary } \\
\text { schools within the country, but was excluded from the curriculum of most of the basic educational } \\
\text { schools in the country. Thus, there was little chance of including agricultural IK in the formal education } \\
\text { system }\end{array}$
\end{tabular}

Resistance to change $(66.9 \%$, or 121$)$

Lack of IK records $(66.3 \%$, or 120$)$

Poor knowledge sharing culture $(64.1 \%$, or 116$)$

Lack of a resource centre $(61.9 \%$, or 112$)$

Lack of trust $(56.4 \%$ or 102)

Socio-economic factors $(44.2 \%$, or 80$)$

Lack of appropriate IPRs $(39.2 \%$, or 71$)$

Disappearance of traditional seeds, plant species and traditional medicine $(17.1 \%$, or 31$)$

Disappearance of culture and practices that are important for $\mathrm{KM}$ activities $(11 \%$, or 20$)$
Negative attitudes and lack of awareness, as well as lack of interest in learning from each other inhibited the acquisition of IK through the existing social structures in the local communities, such as apprenticeships, folklore.

Most IK was preserved in the human mind and was not documented. There were no village journalists to report farmers' issues to the outside world and thus most of the farmers' knowledge was location specific.

Little cooperation from knowledgeable farmers limited access to knowledge. Most respondents reported that they did not have a culture of sharing their knowledge, and the village leaders did not encourage them to do so.

Only one village (Kasiki Village in Kilosa) was located near the district library. Other surveyed villages were located very far from district or regional public libraries

Some farmers did not trust the advice they received from their fellow farmers for various reasons such as bad motives for giving advice, and ineffectiveness of some indigenous techniques to solve farming problems, such as control of plant and animal diseases

Differences in age, gender, social, and economic status limited farmers in acquiring IK from their fellow farmers or village leaders. Most of the elderly people did not want to learn from the present generation, while progressive farmers ignored IK, and did not want to learn or share their knowledge with the poor farmers. Most of the poor farmers relied on their IK due to lack of funds to acquire external inputs, and thus their knowledge was limited to their own circle of families and friends. For instance, one farmer at Kasiki Village in Kilosa reported that, "I am poor and I can not afford to have a big plot for my farming activities. Thus, I am scared to observe other people's farms because I will be suspected of having bad motives."

Farmers felt that their fellow farmers would benefit once their knowledge was made public. Others felt that their knowledge would be used by the pharmaceuticals to manufacture drugs. In actual fact, some IK holders required payment for their services especially knowledge on herbal medicine to control animal and plant diseases in Moshi Rural and Kasulu.

Respondents acknowledged that some of those indigenous plants, seeds and medicinal plants had disappeared due to over population, drought and migration from one place to another especially with a nomadic pastoral society. For instance, the pastoralists of Kilosa (Twatwatwa Village) acknowledged that they had lost a lot of local herbs used for treating their cattle diseases when they practiced nomadic pastoralists. They have changed from nomadic to transhumance pastorals due to land scarcity, globalisation and education issues.

Most of the traditional cultures had disappeared due to modernisation, technology, population pressure and education. These cultures included team working in the farming activities in Songea Rural and Kilosa, specific dates for meetings at the village office in order to exchange ideas in Moshi Rural (Lyasongoro Village), exchange of seed and animal breeds, folklore activities, such as traditional dances. On the other hand, the disappearance of indigenous techniques such as long-term fallowing, granaries and traditional irrigation system had also discouraged some farmers from acquiring knowledge.

Difficulties in identifying It was difficult to identify IK holders and where these IK holders were located due to a lack of established knowledge bearers $(9.9 \%$, structures to identify them

or 18) 
Figure 1: Barriers that hinder sharing of agricultural indigenous knowledge. $(\mathrm{N}=181)$
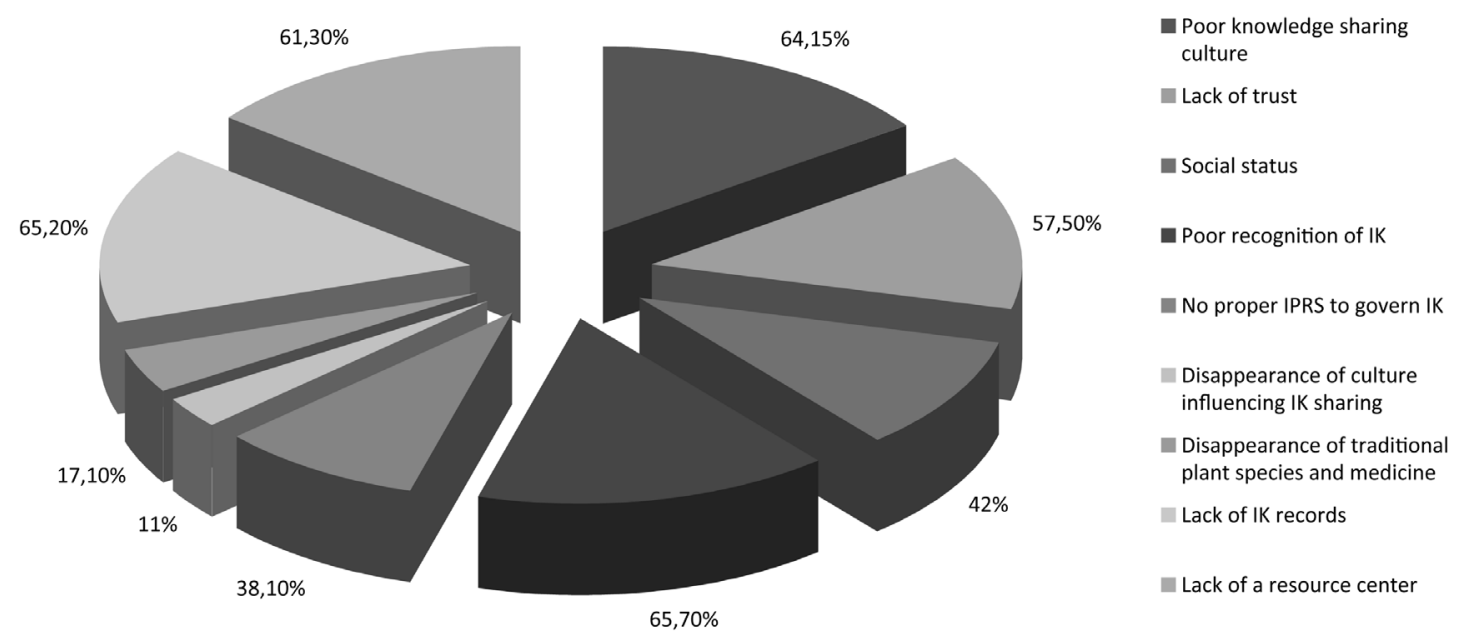

Among those with formal schooling (84\%, or 152), male respondents dominated the higher education category.

\section{Barriers that inhibit the acquisition of agricultural indigenous knowledge}

The main problems that faced farmers when acquiring agricultural IK were poor recognition of IK and resistance to change, with a score of $66.9 \%$ (121) each (see Table 1). Other common problems as identified from the study findings were lack of IK records $(66.3 \%$, or 120$)$, a poor knowledge sharing culture $(64.1 \%$, or 116$)$, lack of a resource centre (61.9\%, or 112$)$, and lack of trust $(56.4 \%$, or 102$)$.

Other factors, identified during the interviews, that inhibited farmers from acquiring IK in the surveyed communities included: conflicts within families; the time-consuming preparation of agricultural indigenous inputs, for instance using local herbs, discouraged farmers from acquiring the IK relating to them; unavailability of extension officers to train farmers on agricultural indigenous techniques; and the disappearance of vernacular languages. Local languages were disappearing at a high rate due to the formal education system which had entirely excluded these languages from the curriculum. The settlement of newcomers in the area and intermarriage with partners from a different ethnic background had also contributed to the disappearance of vernacular languages. In fact, interviews with some elderly people had to be conducted with a translator because they were not familiar with the national language Swahili, or with the English language.
Other barriers included the following: IK was not suitable for large scale farming as compared to contemporary technologies; illiteracy inhibited some farmers from reading printed materials; and some traditional structures, customs and taboos inhibited farmers from acquiring IK in the surveyed communities. For instance, some of the knowledge, for example of local herbs and blacksmithing, was transmitted through inheritance or only existed in specific clans, and thus it was not shared with the whole community (in Kasulu, Moshi Rural, Karagwe). Another barrier was that some indigenous techniques were not effective in solving farmers' problems, and thus some farmers were discouraged from acquiring and using IK. Typical responses included:

"... neem tree juice is not effective to treat Newcastle poultry disease, while vaccines are effective in controlling the disease."

“... I used traditional herbs to treat three cattle and one died, so this knowledge is not effective since I have already experienced a loss."

\section{Barriers that inhibit the sharing of agricultural indigenous knowledge}

It was evident from the study findings that poor recognition of agricultural IK $(65.7 \%$, or 119$)$, was a major barrier which inhibited farmers from sharing IK (see Figure 1). Other common barriers were a poor knowledge sharing culture $(64.1 \%$, or 116$)$, lack of a knowledge resource centre, $(61.3 \%$, or 111$)$, 
Figure 2: Barriers that hinder the preservation of agricultural indigenous knowledge. $(\mathrm{N}=181)$
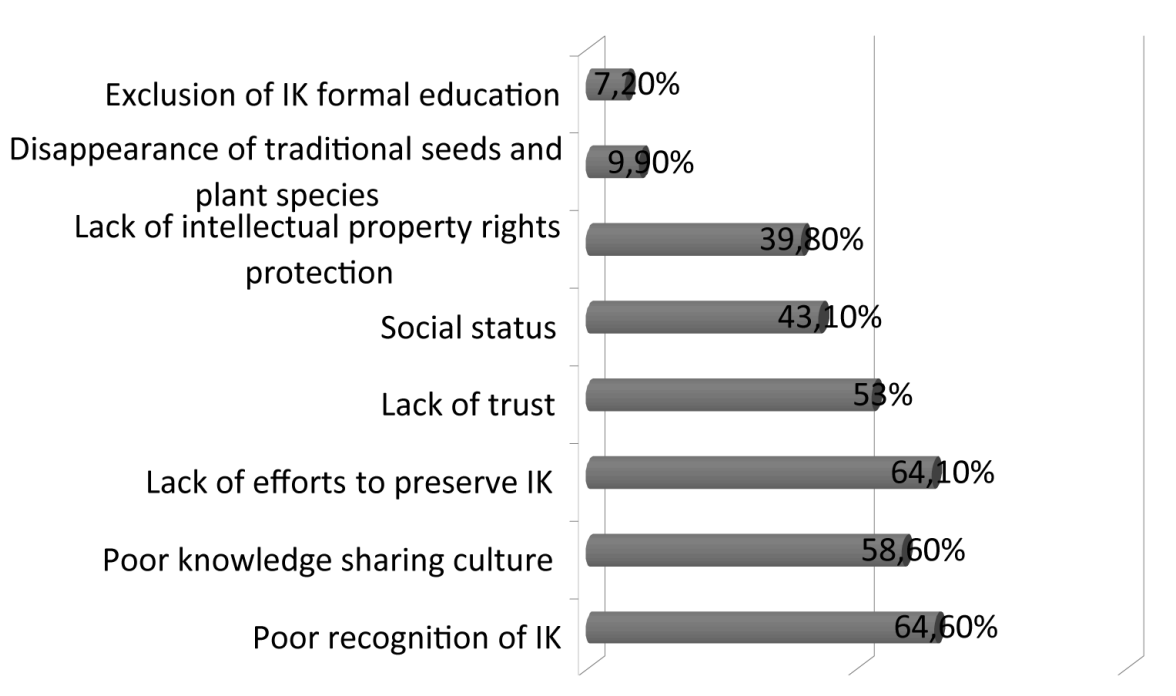

lack of trust $(57.5 \%$, or 104), and social-economic status $(42 \%$, or 76$)$.

Other factors that inhibited farmers from sharing IK, as identified in the category of "other barriers" during interviews, included the following: selfishness; occurrence of conflicts within families; disappearance of vernacular languages; use of conventional technologies undermining the sharing and use of indigenous techniques; traditional structures, customs and taboos; some IK holders requiring payment to share their knowledge, and illiteracy.

\section{Barriers that hinder the preservation of agricultural indigenous knowledge}

The study findings further demonstrated that poor recognition of IK $(64.6 \%$, or 117$)$ and lack of efforts to preserve IK $(64.1 \%$, or 116$)$ were the main barriers to preserving agricultural IK in the communities (see Figure 2). Other common barriers were a poor knowledge sharing culture $(58.6 \%$, or 106$)$, lack of trust $(53 \%$, or 96 ), and social status $(43.1 \%$, or 78$)$.

Other factors that inhibited farmers from sharing IK, as identified in the category of "other barriers" during interviews, included the following: most IK was preserved in the memory of elders and is lost; the dominant use of exogenous technologies had undermined the preservation of IK; traditional structures, customs and taboos had inhibited sharing of some indigenous techniques (such as knowledge of indigenous medicines, and blacksmithing); and the high illiteracy levels of the early custodians of IK had undermined its preservation.

\section{Barriers that hinder access to external agricultural knowledge}

The major problem that limited farmers from accessing external agricultural knowledge were poor extension services $(79 \%$, or 143$)$, which were characterised by the following: public extension officers were either not available, or they were few in number; lack of follow up by public extension officers; lack of access to timely agricultural knowledge, and lack of female extension officers to cater for women's information and knowledge needs. For instance, one respondent in Songea Rural (Matetereka Village) reported that,

"There are no female extension officers in our village, so the extension officer only contacts my husband. Thus, it would be better if there were female extension officers."

Other notable problems were a lack of access to information materials $(73.5 \%$, or 133$)$, lack of a resource centre $(72.4 \%$, or 131$)$, and the low level of literacy $(65.2 \%$, or 118$)$. Other factors that inhibited farmers from accessing external agricultural knowledge, as identified during interviews, included the following: farmers who were trained by the extension officers were not willing to share their knowl- 
Table 2: Barriers that hinder the use of ICTs to manage indigenous and external knowledge on farming systems. $(\mathrm{N}=181)$

\begin{tabular}{|c|c|}
\hline Barrier & Explanation \\
\hline $\begin{array}{l}\text { High cost of ICT } \\
(84 \%, \text { or } 152)\end{array}$ & $\begin{array}{l}\text { Many ICTs such as television and mobile phones were expensive for most farmers. Costs to maintain } \\
\text { ICTs were also high such as charges for using internet and email from telecentres, airtime for mobile } \\
\text { phones, recharging power for mobile phones, batteries for radio, and electricity power. For instance, it } \\
\text { was } 500 \text { Tshs (U.S. \$0.33) to recharge a mobile phone in Kilosa (Twatwatwa Village), which was very } \\
\text { expensive for most farmers. }\end{array}$ \\
\hline $\begin{array}{l}\text { Lack of electricity } \\
(71.3 \% \text {, or } 129)\end{array}$ & $\begin{array}{l}\text { Most of the interviewed farmers did not have electricity which limited the use of some ICTs such as } \\
\text { television. }\end{array}$ \\
\hline $\begin{array}{l}\text { Lack of local and relevant } \\
\text { content } \\
(67.4 \% \text {, or } 122)\end{array}$ & $\begin{array}{l}\text { Most of the television and radio broadcasts tended to focus on entertainment programmes with a few } \\
\text { programmes on agriculture. Internet also lacked relevant and local content which limited communities' } \\
\text { access to knowledge. One farmer at Lyasongoro Village in Moshi Rural reported that, "I normally access } \\
\text { a lot of information from the internet but I have never managed to access agricultural knowledge that suits } \\
\text { my local context." }\end{array}$ \\
\hline $\begin{array}{l}\text { Lack of awareness } \\
(65.7 \%, \text { or } 119)\end{array}$ & $\begin{array}{l}\text { Most farmers were not aware of the importance of ICTs such as the internet to access indigenous and } \\
\text { external knowledge for their farming activities }\end{array}$ \\
\hline $\begin{array}{l}\text { ICT illiteracy } \\
(63 \%, \text { or } 114)\end{array}$ & $\begin{array}{l}\text { Most farmers lacked skills on how to use computers, internet and mobile phones to access agricultural } \\
\text { knowledge and information. }\end{array}$ \\
\hline $\begin{array}{l}\text { Poor ICT infrastructure } \\
(57.5 \%, \text { or } 104)\end{array}$ & Included poor coverage of both television and radio broadcasts, as well as mobile phone networks \\
\hline $\begin{array}{l}\text { Lack of telecentres } \\
(45.9 \% \text {, or } 83)\end{array}$ & $\begin{array}{l}\text { Some communities were located very far from telecentres such as Kasulu (Kidyama Village), Kilosa } \\
\text { (Twatwatwa Village), Mpwapwa (Vinghawe Village), Karagwe (Katwe Village), and Songea Rural } \\
\text { (Matetereka Village). }\end{array}$ \\
\hline
\end{tabular}

edge due to selfishness, and memory lapses. Other related problems from the present findings were resistance to change; social-economic factors (such as age, gender, status); lack of funds to purchase information materials and paying library membership fees to borrow books; lack of a knowledge sharing culture to share and learn from each other, such as to attend village meetings or training on farming practices; village leaders not encouraging farmers to share their knowledge; and village meetings occurring infrequently.

Some problems related to farmer groups and included the following: lack of awareness on the importance of farmer groups; resistance to joining farmer groups due to old age; lack of sensitisation and encouragement from the village leaders; inaccurate perceptions about farmer groups; and late delivery of inputs. Other problems included the unavailability and/or high cost of inputs; lack of awareness of the available information services; distant locations, such as agricultural shows that were usually held in regions and zones that were far from the villages; lack of a bookshop; and the ineffectiveness of some attempts at using conventional inputs to solve farming problems. For instance, one farmer in Kilosa (Kasiki Village) reported that, "I have tried to vaccinate poultry to prevent them from Newcastle disease by using conventional vaccines, but I have never been successful."

\section{Barriers that inhibit the use of ICTs to manage indigenous and external knowledge on farming systems}

The high cost of ICTs (84\%, or 152) was the major barrier that limited farmers in managing agricultural indigenous and external knowledge through ICTs (see Table 2). Lack of electricity $(71.3 \%$, or 129$)$ was the second most cited problem, followed by the lack of local and relevant content $(67.4 \%$, or 122$)$.

Other problems identified during the interviews were related to the radio and television broadcasts, such as the short period of time allotted to the programmes, programmes not being consistently aired and poor quality, poor timing, and broadcasts not being participatory. Farmers preferred information and knowledge to be delivered through participatory approaches and in the printed format for future reference. It was difficult for farmers to understand, memorise and implement what they had learnt from 
Table 3: Common barriers affecting access to external knowledge, acquisition, sharing, and preservation of IK and ICT use of Agricultural indigenous and external knowledge. $(\mathrm{N}=181)$

Barriers

\begin{tabular}{|c|c|c|}
\hline 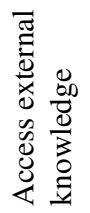 & 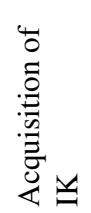 & 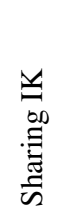 \\
\hline
\end{tabular}

Personal

Poor recognition of IK

Lack of interest \& awareness

Selfishness

Time constraints

Age

Gender

Socio-economic status

Illiteracy

Resistance to change

Poverty

Poor communication skills

Lack of trust

Social

Lack of knowledge sharing culture

Language barriers \& disuse of vernacular languages

Ignorance of who IK holders are

Conflicts in families

Traditional structures, customs \& taboos

External environment

Inadequate government efforts to recognise \& record IK

Insufficient extension officers \& training programmes

Lack of IPR to protect IK

Lack of IK in formal education system

Poor communication \& documentation

Poor management of farmers' groups

Lack of leadership

Costs of agricultural inputs e.g. fertilizers

Distant locations

Lack of rural resource centres \& information materials

Ineffectiveness of some indigenous techniques

$\begin{array}{lllll}\sqrt{ } & \sqrt{ } & \sqrt{ } & \sqrt{ } & \\ & & & \sqrt{ } & \sqrt{ } \\ \sqrt{ } & \sqrt{ } & \sqrt{ } & & \\ \sqrt{ } & \sqrt{ } & \sqrt{ } & & \sqrt{ } \\ \sqrt{ } & \sqrt{ } & & \sqrt{ } & \sqrt{ } \\ \sqrt{ } & \sqrt{ } & & \sqrt{ } & \sqrt{ } \\ \sqrt{ } & \sqrt{ } & \sqrt{ } & \sqrt{ } & \sqrt{ } \\ \sqrt{ } & \sqrt{ } & \sqrt{ } & \sqrt{ } & \sqrt{ } \\ \sqrt{ } & \sqrt{ } & & & \\ \sqrt{ } & & & & \sqrt{ } \\ \sqrt{ } & & & & \\ \sqrt{ } & \sqrt{ } & \sqrt{ } & \sqrt{ } & \end{array}$

Lack of infrastructure

$\begin{array}{lllll}\sqrt{ } & \sqrt{ } & \sqrt{ } & \sqrt{ } & \\ \sqrt{ } & \sqrt{ } & \sqrt{ } & & \sqrt{ } \\ & \sqrt{ } & & \sqrt{ } & \\ & \sqrt{ } & \sqrt{ } & \\ & \sqrt{ } & \sqrt{ } & \sqrt{ }\end{array}$

Political constraints

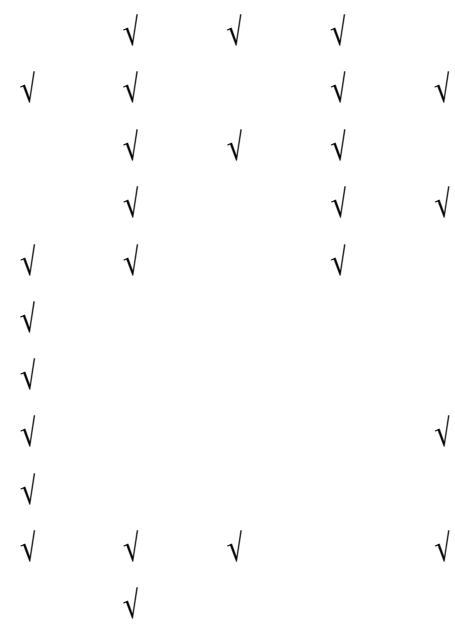

$\begin{array}{ll}\sqrt{1} & \sqrt{ } \\ \sqrt{ } & \sqrt{ }\end{array}$

Key: $\mathrm{v}=$ constraints to access, acquisition, sharing and preservation and ICT use of agricultural IK 
radio or TV broadcasts. For instance, one farmer in Kilosa (Kasiki Village) reported that,

"I heard about the use of fertiliser from the radio. However, it was difficult for me to apply the technique because I could not remember."

Socio-economic factors (such as age, gender, social and economic class) also limited farmers who did not own ICTs in using their neighbours' ICTs (such as radio, TV or mobile phones) to access knowledge. Other barriers were language; low priority being accorded to ICTs; lack of follow up from professionals; widespread cases of theft limited farmers in acquiring ICTs; and lack of assistance on the use of ICTs to market farmers' produce. For instance, one farmer in Moshi Rural reported that,

"I was able to secure a buyer for my banana crops through [the] Internet. However, I was not able to sell those [that] produce due to [a] lack of government assistance on online marketing."

\section{Discussion of findings}

Many of the barriers occurred as common barriers across the activities of accessing, acquiring, sharing and preserving external agricultural IK and in the use of ICTs. To avoid excessive repetition and to showcase these commonly occurring barriers more effectively the greater part of the discussion in this section takes the form of a table. Comment on issues relating to the contents of the table follows under two headings. Table 3 below lists the common barriers identified by the study.

Illiteracy and socio-economic status emerged as a factor which affected all the activities negatively, followed by poor recognition of IK, lack of trust, lack of a knowledge sharing culture, language barriers and disuse of vernacular languages, insufficient extension officers and training programmes, and lack of rural resource centres and information materials.

\section{Barriers that inhibit the access to external agricultural knowledge, acquisition, sharing and preservation of agricultural indigenous knowledge}

Poor recognition of the IK system, especially by the current generation, is mainly due to inadequacies of the formal education system, socialisation and the development of ICTs where indigenous knowledge is excluded. Similar observations were made in another study in Uganda (Agea et al. 2008).

Various personal and social factors contributed to an unwillingness of farmers to share their knowledge with fellow farmers resulting in a significant barrier to knowledge acquisition. Notably, those farmers trained by extension officers were the most reluctant to share their knowledge, a problem which Dixon (2002) found also occurring in Ethiopia. Probst, Raub and Romhardt $(2000,193)$ argue that the ability to share knowledge depends primarily on the individual's talent for communication, the pride in ownership of one's own expert knowledge, available time and fear of endangering one's own position in the community once knowledge has been shared. According to Rowley (2001) this can only be changed if individuals are convinced of the need to share knowledge. In this respect, von Krogh, Ichijo and Nonaka $(2000,49)$ suggest that care in terms of mutual trust, active empathy, access to help, lenience in judgement and courage can enable people to share their insights and freely discuss their concerns. Social factors determine the extent to which people who possess the knowledge are willing to share it and place it in the social domain (Jashapara 2004), and in this study the absence of a knowledge sharing culture combined with the disappearance of the vernacular languages in which the knowledge is expressed inhibited both the sharing and use of IK.

In addition, as with Agea et al.'s (2008) Ugandan study, the failure to maintain adequate records and preserve IK meant that much of it is being lost, further undermining food security in the region. The very real danger exists that if not preserved, IK may disappear altogether leaving farmers with neither traditional nor conventional agricultural abilities (Dinucci and Fre 2003).

Other problems existed related to external factors which could not be solved by individuals or the local communities. Predominant was the failure of government to recognise IK resulting in the lack of necessary policies, plans, personnel and infrastructure needed to promote the use of indigenous knowledge and enable farmers' access to available information. Indications are that access to relevant knowledge may enable the communities to improve their agricultural activities. There is a need for both private and public sectors to improve agricultural extension and information services, to improve infrastructure 
in the rural areas, and provide timely and relevant farm inputs. This finding was similar to that of Wambura et al. (2007) who noted that poor leadership and lack of a constitution were found to be key factors that inhibited farmer groups in accessing knowledge, inputs and markets in the rural areas of Morogoro region in Tanzania.

\section{Barriers that inhibit the use of ICTs to manage indigenous and external knowledge on farming systems}

In addition to the common personal, socio-cultural and external environmental barriers, technical barriers presented unique problems associated with ICT awareness and skills. Insufficient technical assistance together with badly timed and scheduled radio and television broadcasts rendered ICTs ineffective. Since radio broadcasts were the most preferred mechanism for knowledge acquisition and sharing in the local communities, technical issues such as timing, sustainability and continuity need to be considered in future agricultural development programs. Similarly, a South African study of rural ICT projects identified the following barriers that limited use of ICTs: infrastructure access, illiteracy, content, education levels, insufficient training and capacity building, financial, political, social and cultural constraints (Pade 2006).

\section{Conclusions and recommendations}

The findings showed that farmers faced various challenges which inhibited them in managing their IK, accessing external knowledge, and using ICTs to manage their knowledge. Barriers with regard to the management of IK, and access to external knowledge included personal and social barriers, the external environment such as infrastructure, policy, Intellectual Property Rights, and weak linkages between research, extension and farmers. Farmers also faced challenges with regard to the use of ICTs to manage their knowledge, which were related to personal, socio-cultural, infrastructural, technical, and economic factors. Despite the fact that some problems can be solved by the individual farmers and their communities, other problems would require public and private sector effort to improve the management of IK, access to external knowledge and use of ICTs for KM activities in the local com- munities. There is a need for public and private institutions and the communities to engage collectively in an effort to recognise the power of IK which is mainly tacit, and to manage and link it with external knowledge for improved farming activities. IK should not be separated from the individuals who hold it; instead efforts should be made to enable the communities to innovate, create, share and preserve their own knowledge, and to adapt other knowledge systems for sustainable agricultural growth in subSaharan Africa.

Based on the findings, this study recommends that the rural knowledge providers (that is, agricultural extension officers, researchers, educators, libraries, NGOs, civil societies, and other agricultural actors) and village leaders nurture a knowledge sharing culture to enable farmers to change their attitude towards accepting, sharing and using IK together with new knowledge. They can do this by creating an awareness of the value of knowledge to enable farmers to change their attitudes towards acquiring and sharing IK together with new knowledge; by strengthening the existing social networks such as farmer groups to cultivate communities of practice; by creating space and time for farmers to meet and share their knowledge through fora, and by encouraging the active use of storytelling and narratives when sharing knowledge in the individual and collective interactions in the community, such as farmer groups, village meetings, and other informal networks. Stories are a powerful way of understanding what happened in a sequence of events and the causes of why the events took place (Brown and Duguid 2000). Knowledge providers should also encourage the use of indigenous communication channels when sharing knowledge in individual and collective interactions, especially in those areas where oral tradition still prevails. Those channels include apprenticeships, initiation rites in adolescence, and the use of folklore embodied in songs, drama and traditional dances. They should also encourage the active participation in individual and collective interactions, and persuade farmer groups to establish linkages with other farmer groups that exist in other communities. These linkages should be characterised by exchange visits, regular group training, demonstrations and meetings.

To prevent knowledge loss, the knowledge providers and public and private partners should train farmers to capture and preserve their knowledge 
in multiple formats (oral, print and ICT). Knowledge providers should combine face-to-face communication with other media such as print, ICTs and indigenous communication channels including traditional communication channels (i.e. folklore, apprenticeships) specific to a local context when disseminating knowledge and information in the local communities. Print formats and ICTs such as radio, mobile phones, Internet, and emails can be used to share and distribute knowledge among farming communities to supplement what was gained verbally.

These providers should work jointly with the communities to establish rural knowledge resource centres, where the documented knowledge would be preserved. Further, the rural knowledge providers should use knowledge maps to identify and document the whereabouts of IK bearers so that the local people can easily locate knowledge sources in their communities. These knowledge maps can be printed and made available in rural libraries, sent as a message by mobile phones, and publicised through the community radio, telecentre websites, and posters. They should create awareness of IK bearers and innovators in the communities to enable farmers to access IK.

For effective access of external knowledge in the communities, knowledge providers should use participatory approaches in the production and dissemination of knowledge in order to include farmers' needs and knowledge in the developed technologies, practices and knowledge. Use of participatory approaches will enable the knowledge providers to learn from farmers' own experience and farmers to learn from the providers and their fellow farmers in order to share and create new knowledge. Knowledge providers can use participatory approaches in the following: research and extension services (e.g. farmer field schools), production of radio and TV broadcasting programmes, production of print media such as brochures, posters, newsletters, and development of content for internet. In this sense, the linkages of indigenous and exogenous knowledge would be feasible.

The government should also improve its extension and research services by increasing the number of extension officers. These extension officers should have regular training programmes to update their skills in indigenous farming system. Thus, the integration of indigenous and exogenous knowledge would be possible. Further, the government should also review the current IPR system in an attempt to recognise and assert ownership over IK and genetic resources and protect it from improper commercial use. The government should institute an IK policy which should address the protection of IK, management of IK, incorporation of IK into the mainstream knowledge systems, gender and the capacity building issues for both the communities and knowledge providers. The current IPR system should be reviewed to address issues related to the protection of IK and genetic resources. Public and private institutions, and knowledge providers should create awareness and train farmers on IPR issues to enable them to register for benefit sharing of their local innovations. Regarding infrastructure, the government should focus on the improvement of rural electrification, telecommunication signals, road infrastructure, and access to other affordable power sources such as solar power for effective use of ICTs for KM practices in the local communities.

\section{Limitations of the study and suggestions for further research}

This study provides a way of understanding the challenges of acquiring, sharing and preserving indigenous knowledge, accessing external knowledge, and use of ICTs for managing both indigenous and external knowledge in the local communities of Tanzania. A way forward would be to conduct a research study through mixed research methods to analyse the specific barriers and opportunities for identifying, creating, acquiring, sharing, preserving, and using both indigenous and external knowledge in the local communities of sub-Saharan Africa. Further research may be conducted to assess the challenges of managing indigenous and external knowledge in other sectors, such as health sector, since most of sub-Saharan Africa's population relies on traditional and indigenous health care systems for their primary health care needs.

\section{References}

Agea, J. G., E. Lugangwa, J. Obua, and R. K. Kambugu. 2008. "Role of Indigenous Knowledge in Enhancing Household Food Security: A Case Study of Mukungwe, Masaka District, Central Uganda." INDILINGA: African Journal of Indigenous Knowledge Systems 7(1): 64-71.

Asaba, J. F., R. Musebe, M. Kimani, R. Day, M. Nkonu, A. Mukhebi, A. Wesonga, R. Mbula, P. Balaba, and A. Nakagwa. 
2006. "Bridging the Information and Knowledge Gap between Urban and Rural Communities through Rural Knowledge Centres: Case Studies from Kenya and Uganda." International Association of Agricultural Information Specialists (IAALD) Quarterly Bulletin 51(3-4): 143-151.

Brown, John Seely, and Paul Duguid. 2000. The Social Life of Information. Cambridge, MA: Harvard Business School Press.

Cohen, L., L. Manion, and K. Morrison. 2007. Research Methods in Education. 6th ed. London: Routledge Falmer.

Dinucci, A., and Z. Fre. 2003. Understanding the Indigenous Knowledge and Information Systems of Pastoralists in Eritrea. Rome: Food and Agriculture Organization of the United Nations, Communication for Development Case Study 26. Accessed November 20, 2010. ftp://ftp.fao.org/docrep/fao/006/ Y4569E/Y4569E00.pdf.

Dixon, A. B. 2002. "The Role of Indigenous Knowledge in Wetland Management: Mechanisms of Knowledge Acquisition and Development Basis for Sustainable Use." Huddersfield, UK: Wetlands and Natural Resources Research Group, WeNReG Working paper 4. Accessed June 3, 2010. http:// wetlands.hud.ac.uk/pdf/WP4.pdf.

Dove, M. R. 2000. "The Life-Cycle of Indigenous Knowledge and the Case of Natural Rubber Production." In Indigenous environmental knowledge and its transformations, edited by R. Ellen, P. Parkes, and A. Bicker, 213-254. Amsterdam: Harwood Academic Publishers.

Hårsmar, M. 2007. "Introduction.” In Agricultural Development in Sub-Saharan Africa: Workshop Proceedings, Frösundavik 8-9 March 2006, edited by M. Hårsmar, 9-16. Stockholm: Ministry for Foreign Affairs, Expert Group on Development Issues. Accessed November 15, 2010. http://www.fanrpan. org/documents/d00464/Agric_dev_SSA_EGDI_2007.pdf.

Jashapara, A. 2004. Knowledge Management: An Integrated Approach. Harlow: Pearson Education.

Langill, S. 1999. Indigenous Knowledge: A Resource Kit for Sustainable Development Researchers in Dryland. Ottawa: IDRC.

Lemma, M., and V. Hoffmann. 2005. "The Agricultural Knowledge System in Tigray, Ethiopia: Empirical Study about its Recent History and Actual Effectiveness." Paper presented at The Global Food and Product Chain: Dynamics, Innovations, Conflicts, Strategies, Tropentag 2005: International Research on Food Security, Natural Resource Management and Rural Development, Stuttgart-Hohenheim, 11-13, October 2005. Accessed June 23, 2011. http://www.tropentag. de/2005/proceedings/node152.html\#2487.

Lieberman, A. E. 2008. "Taking Ownership: Strengthening Indigenous Cultures and Languages through the Use of ICTs." Washington, D.C.: LearnLink, Academy for Educational Development. Accessed September 20, 2010. http://learnlink. aed.org/Publications/Concept_Papers/taking_ownership.pdf.

Lwoga, E. T. 2011. "Knowledge Management Approaches in Managing Agricultural Indigenous and Exogenous Knowledge in Tanzania." Journal of Documentation 67(3): 407430.

Lwoga, E. T., and P. Ngulube. 2008. "Managing Indigenous and Exogenous Knowledge through Information and Communication Technologies for Agricultural Development and

Achievement of the UN Millennium Development Goals." In Libraries and Information Services towards the Attainment of the UN Millennium Development Goals, edited by B. Njobvu and S. Koopman, 73-88. Berlin: Walter de Gruyter.

Lwoga, E. T, P. Ngulube, and C. Stilwell. 2010. "The Relevance of Indigenous Knowledge for Small-Scale Farming in Tanzania." INDILINGA - African Journal of Indigenous Knowledge Systems 9(1):12-28.

Mascarenhas, A. 2003. "Indigenous Knowledge, Livelihood and Development: Is a High Rate of Sustainable Growth Achievable?" Paper presented at Inaugural Tanzanian Biennial Development Forum, Dar es Salaam Tanzania, 24-25 April 2003. Accessed April 10, 2010. http://www.tzonline.org/pdf/ indigenousknowledgelivelihood.pdf.

Mchombu, K. J. 1995. "Researching Rural Information Provision: A Case Study." In Seminar on Information Provision to Rural Communities in Africa: proceedings of the seminars, Gaborone, Botswana, 22-25 June 1994, edited by E. Johansson, 124-130, Uppsala: Uppsala University Library (IFLA Project Report no. 3).

Mella, E. E., K. Kulindwa, F. Shechambo, and S. Mesaki. 2007. "The Integrated Assessment of Organic Agriculture in Tanzania: Policy Options for Promoting Production and Trading Opportunities for Organic Agriculture." Accessed December 10, 2010. http://www.unep-unctad.org/cbtf/publications/ Integrated $\% 20$ Assessment $\% 20$ of $\% 20$ the $\% 200 A \% 20$ Sector $\%$ 20in\%20Tanzania.pdf .

Ngendello, A. M., M. S. R. Byabachwezi, and T. Schrader. 2003. "Dissemination of Agricultural Technology: Narrowing the Gap between Research, Extension and Farmers." In Managing Research for Agricultural Development. Proceedings of the National Workshop on Client Oriented Research, edited by N.M. Lema, C. Schouten, and T. Schrader, 142153. Amsterdam: KIT.

Ngulube, P. 2002. "Managing and Preserving Indigenous Knowledge in the Knowledge Management Era: Challenges and Opportunities." Information Development 18(2): 95-100.

Pade, C. I. 2006. “An Investigation of ICT Project Management Techniques for Sustainable ICT Projects in Rural Development." Masters thesis: Rhodes University. Accessed June 2, 2010. http://eprints.ru.ac.za/900/01/Pade-MCom-TR07-99.pdf.

Probst, G., S. Raub, and K. Romhardt. 2000. Managing Knowledge: Building Blocks for Success. New York: John Wiley.

Robinson, D, and R.G. Mutakyahwa. 2004. An Introduction to the Non-profit Sector in Tanzania. London: Allavida.

Röling, N. G. 1989. The Research/Extension Interface: A Knowledge System Perspective. The Hague, Netherlands: The International Service for National Agricultural Research.

Rowley, J. 2001. "Knowledge Management in Pursuit of Learning: The Learning with Knowledge Cycle." Journal of Information Science 27(4): 227-237.

Teddlie, C., and A. Tashakkori. 2009. Foundation of Mixed Methods Research: Integrating Quantitative and Qualitative Approaches in the Social and Behavioural Sciences. Thousands Oaks, CA: Sage.

Van Vlaenderen, H. 2000. "Local Knowledge: What is it, and Why and How do we Capture It?" In Gender, Biodiversity and Local Knowledge Systems (LinKS) to Strengthen Agricultural and Rural Development (GCP/RAF/338/NOR): Selected Papers from the First National Workshop held in Morogoro, 22-23 June, 1999, edited by A.S. Kauzeni, 1-11. FAO Links report 3. Accessed February 2, 2011. http:// 
www.fao.org/sd/LINKS/documents_download/Selected $\% 20$ papers\%20Morogoro\%2099.pdf.

Von Krogh, G., K. Ichijo, and I. Nonaka. 2000. Enabling Knowledge Creation: How to Unlock the Mystery of Tacit Knowledge and Release the Power of Innovation. New York: Oxford University Press.

Wambura, R. M., D. F. Rutatora, R. Øygard, M. Shetto, and O. Ishumi. 2007. "The Experience of Small Farmer Group (SFG) Organisations in Promoting Agricultural Extension in Tanzania." South African Journal of Agricultural Extension 36(1): 39-52.
World Summit on the Information Society (WSIS). 2003. "The Geneva Declaration of the Global Forum of Indigenous Peoples and the Information Society 2003." Accessed March 6, 2010. http://www.worldsummit2003.de/en/nav/14.htm.

Editorial history:

Paper received: 6 November 2010

Revised version received: 6 April 2011

Accepted: 15 April 2011 
Copyright of Libri: International Journal of Libraries \& Information Services is the property of De Gruyter and its content may not be copied or emailed to multiple sites or posted to a listserv without the copyright holder's express written permission. However, users may print, download, or email articles for individual use. 